\title{
The fifth archetype of electricity market: the blockchain marketplace
}

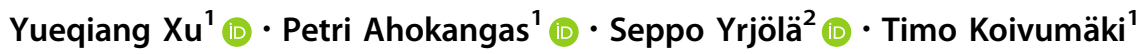

Published online: 3 July 2019

(C) The Author(s) 2019

\begin{abstract}
Enabling and empowering the diverse energy resources to have active yet efficient participation in the smart grid and energy market is an unrivaled challenge for the energy industry. This research expands the four dominant archetypes of business models in the energy and electricity market, creating a fifth archetype, the "blockchain marketplace". The contributions of the study are to identify the extant electricity market designs and architectures as centralized and pseudodecentralized while proposing a fully decentralized architecture enabled by the blockchain. The research contributes to the literature of smart grids and demand-side management and introduces the value configuration/architecture approach for the energy market and business model domains.
\end{abstract}

Keywords Blockchain - Electricity market - Energy market - Smart grid · Business model

\section{Introduction}

Wholly centralized energy utilities were once playing the leading role in the energy industry. The utility's core responsibility is to construct electric networks for reliable and on-demand energy supply for the end energy users. Utility firms once had a basic business model. They make decisions on when and where to build up the generation, transmission and distribution capacities, keeping the energy system in balance, and operating as a controlling entity in the center of the industry.

The expanding energy demand and reliance on fossil fuel has become a worldwide concern [1]. Another key change is the constantly growing volume of distributed energy resources (DERs) integrated into the electric grid.

\author{
Yueqiang Xu \\ yueqiang.xu@oulu.fi \\ Petri Ahokangas \\ petri.ahokangas@oulu.fi \\ Seppo Yrjölä \\ seppo.yrjola@nokia.com \\ Timo Koivumäki \\ timo.koivumaki@oulu.fi \\ 1 Martti Ahtisaari Institute, OBS, University of Oulu, Pentti \\ Kaiteran katu 1, P.O. Box 4600, 90014 Oulu, Finland \\ 2 Nokia, Kaapelitie 4, 90620 Oulu, Finland
}

DERs posed unparalleled challenges to balancing the electricity supply and demand in the network as well as maintaining a resilient concurrent electric infrastructure [2]. Therefore, today's electric systems have been facing significant changes, transitioning away from the paradigm of centralization [3].

According to [4], the power balance between energy end users and centralized utilities is shifting due to the advent of Information and Communication Technologies (ICTs) and the integration of the ICT technologies in the grid operation. The DER is on the rise, which is moving the grid balancing responsibility of the traditional energy companies to the demand side, where energy users are empowered to have a cleaner and more robust energy system. Thus, Demand Side Management (DSM) (including Energy Efficiency, Time of Use, and Demand Response) becomes critical. From DSM's perspective, the integration of communication technology into DSM is key. As suggested by [5], using the load as additional demand flexibility is not an entirely new idea, but the use of affordable communication infrastructure makes it possible and relatively easy to add "smartness" to the loads. Numerous studies address the need to move this revolution into the mainstream and create a new model or design for the DSM in the energy market that puts consumers in charge of a cocreated energy future $[6,7]$.

As the European Union (EU) has rolled out a challenging directive for the energy future, namely, the "Clean 
Energy for All Europeans" package [8], there is a strong demand on the increase of energy efficiency (from 27 to $30 \%$ ), the further reduction of emissions (reduce by $40 \%$ ), and a higher renewable integration target in the end energy usage $(27 \%)$. However, the ambitious initiatives and goals demand new ways of thinking and new questions to be answered, such as: "how to enable the real and active participation of all the energy stakeholders (including consumers, prosumers, DERs, utilities) within the energy ecosystem, not just the conventional utilities and the regulators?"; and "what can be the new architecture of the energy system and market with new ways of creating and capturing value from a decentralized perspective, supporting the technological development trends entailed by DSM?"

In this vein, we identify an emerging technology, the blockchain as a promising solution to enable the decentralized energy market and peer-focused business models. The blockchain is initially created for the well-known cryptocurrency, Bitcoin [9]. The key characteristics of blockchain are to (1) enable decentralized transaction and data management; (2) maintain and verify the peer-created data records stored in the distributed database [10]. Various industries and technical domains have utilized this technology, such as telecommunications and spectrum sharing [11], the Internet of Things (IoT) [12], and finance [4]. Recent studies show that the blockchain has expanded its applications to energy domain. For example, the technology has been piloted in the areas of solar trading in the US, energy exchange in Austria, and the billing process for autonomous electric vehicle (EVs) charging in Germany [13].

This research focuses on contributing to the research in smart grids and DSM, proposing new energy and electricity market design that can be enabled by blockchain. The specific contributions are: (1) introducing the most recent theoretical development of the business model (value process and value configuration) for the systemic design of the electricity market in the digital age; (2) expanding the four dominant archetypes of business models (mainly orchestrator-driven, from centralization to pseudo-decentralization) with a fully decentralized archetype for the energy market, adding value to the EU's Smart Grid Architecture Model (SGAM); (3) incorporating the value configuration/architecture and business model perspective to propose the theoretical possibility of a fully decentralized electricity market design enabled by the blockchain (the "blockchain marketplace") as opposed to the dominant design of centralized or the semi-liberalized energy market in the literature.

The structure of the paper is as follow: In Sect. 2, the paper presents the four dominant business model archetypes from the resource and value configuration perspective. Section 3 explains the characteristics of blockchain technology and its empirical applications. Section 4 discusses the research methodology. Section 5 proposes the blockchain-based business model as the fifth archetype for the future energy market. The four existing business model archetypes in the energy market are also discussed to provide context and comparison. The last section of the paper includes concluding remarks, research implications, limitations, and future research recommendation.

\section{Related work on the blockchain business model}

This section presents the theories and concepts of business model from a value configuration perspective as well as reviewing the extant blockchain-based business model studies.

\subsection{Business model, value configuration and architecture}

The attention to business model research has been growing exponentially in recent years [14]. Various theoretical perspectives are used to study business model, for instance, business model is analyzed as a system of interrelated components such as resources and capabilities, internal and external structures of an organization and its value network [15], value proposition [16] as well as cost and revenue structure [17]. In the recent literature, a converging conceptualization has emerged, suggesting that three key aspects are concerned with business models, including the opportunity processes (exploration, exploitation) [18], the value architecture, configuration and processes (creation, capture) [19], and advantage establishment [7].

The value logic or thinking, although fragmented in the business model literature, has been considered particularly important for the creation of novel business models and required systemic thinking [20]. At the individual firm level, the value configuration logic is embedded in the well-established activity system theory. According to [21], in the activity system, the activities can be configured to enable the business model to achieve a better strategic position, in other words, the architectural logic means that the business model can be configured or re-configured around efficiency or novelty design [22]. At the ecosystem level, it is suggested by [23] that all types of ecosystems have a modular architecture organized around the value creation and capture associated with the value propositions such as products, technologies, or services.

In the era of digitalization, the scope of resources and competence that a company can access has broadened. 
Thus, we need to expand from the conventional view that the value-based business model and strategy is only about "adding value" to the existing value proposition or value chain [24]. Instead, the value architecture, configuration, and processes require a holistic view for the design of digital business models at the system (or ecosystem) level, in order words, creating the systemic value [7]. Building on the resource orchestration approach [25], the study presents the four archetypes of orchestrator-driven business models as the latest development of architectural logic in the business model research:

- Archetype 1, "firm as an integrator" The orchestrating firm (O) directly transforms the resources and raw materials to create value for customers. This archetype can be found in product business models as a predominant type of resource configuration for conventional firms like manufacturers. This archetype is also considered as a supply-focused business model [14].

- Archetype 2 "firm as a collaborator" The orchestrating firm $(\mathrm{O})$ creates value by working with partners who can complement the orchestrating firm's operation as a simple strategy for resource and value configuration. This archetype is well-known in the strategic alliance [26] and ecosystem studies [27].

- Archetype 3, "firm as a transaction enabler" This archetype can be considered as the platform business model. The orchestrating firm $(\mathrm{O})$ builds two or multisided markets to match the resources and needs of the groups of market participants on each side of the platform. It is a common archetype of the digital business model [28].

- Archetype 4, "firm as a bridge" In this archetype, the orchestrating firm (O) focuses on bridging certain groups of market participants who have not been previously connected through other business models such as a platform model. The orchestrating firm utilizes data as a resource and benefits from connecting the unbridged needs such as Google's advertising model [28].

\subsection{Blockchain-based business models}

Various studies have investigated the blockchain business model at different levels of abstraction [29]. For instance, it is suggested by [30] that the blockchain-enabled business model is generally innovative due to the innovativeness (or potentially disruptiveness) of the blockchain technology as a generic narrative of the blockchain-enabled business model. The study [31] coined the term "blockchain-based sharing economy business models" (BSEBMs) and compared it with the more traditional sharing economy business models (SEBMs) in the related literature, which can be considered as business models at the archetypical level. Another study [32] mapped out how the blockchain can affect the three value aspects of a business model (value proposition, value delivery and value capture) with an ontological representation while, in the same vein, blockchains' impact on the business model's components (strategic components, customer and market components, and value creation components) is analyzed [33]. Another research [34] conducted the comparison of how the blockchain can affect the business models of traditional physical products (those of car manufacturing) versus the models of the service sector (providing software) via the business model canvas [17]. This can be considered as the level of the specific graphical framework. The research [35] suggests that blockchain can affect and improve business processes, including increasing the degree of automation, reducing the intermediaries and paperwork, giving opportunities for audits and data tracking, lowering the risks of fraud and errors, minimizing transactions and processing time, implementing innovative payment instruments and supporting democratic decision-making. This level of abstraction can be considered as relating to the activity system of the business model.

In the energy domain, one of the similar works exploring the blockchain business model [36] classifies seven archetypes of blockchain-based business models in the energy industry (retailers, REC-incentive schemes, proofof-green-power procurement, over-the-counter trading platforms, flexibility-trading platforms, crowd-sale/funding platforms and P2P energy-trading platforms) that are also archetypical conceptualizations of the blockchain-based business model.

\section{Blockchain for decentralized smart grids}

There is an emerging phenomenon of consuming, sharing and liberalizing the access to resources and assets among peers in a collaborative manner. Peer-to-Peer (P2P)-oriented concepts such as the peer economy [37], the sharing economy [38], and collaborative consumption [39] have gained popularity recently. As suggested by [40], blockchain technology is seen as the enabler for these decentralized system architectures and business models. This section will focus on the technical discussion of blockchain technology.

\subsection{Understanding blockchain and smart contract}

According to [9], blockchain is a general-purpose technology that enables decentralized transaction and data management. The key capability of blockchain is to track 
and settle transactions and implement contract enforcement across a diverse range of digital assets, for example, conventional currency, digital currency, IP, data, contracts or physical assets [41]. The extant literature suggests that the blockchain is embodied in a range of existing technologies, such as P2P networks, cryptographic algorithms, distributed data storage, and decentralized consensus mechanisms [40]. Bitcoin, the cryptocurrency, is the very first and prominent example of blockchain applications in practice [9].

As such, blockchain can be seen as a decentralized and distributed database maintaining an ever-growing list of data entries that are confirmed by the nodes participating in the blockchain. Blockchain generates a public ledger that records data on every transaction in the blockchain. A blockchain network is a distributed P2P network with no "middle-man", such as a central server or intermediary. The consensus mechanisms [42, 43] act as the insurance for the coherency of data among the nodes. The utilization of cryptography in the blockchain ensures the authoritativeness behind all transactions [44] as information on every completed transaction is shared and made available to all nodes. Therefore, blockchain enables a more transparent system than centralized solutions [45].

A key element of the blockchain is the smart contract that functions autonomously with self-executing scripts, making general-purpose computations taking place on the blockchain to be entirely predictable [44]. As initially proposed by [46], the smart contract is defined as a computerized transaction protocol that executes the terms and content within a contract, which is often digitalized. All peers in a $\mathrm{P} 2 \mathrm{P}$ blockchain network can audit or inspect the cryptographically verifiable trace of smart contract's operation. As suggested by [44], the smart contract also enables automated workflows that are complex and involve multi-step and distributed processes. There have been numerous applications and use cases of smart contracts that facilitate decentralize operations, for instance, decentralized voting, escrow systems, crowdfunding, auctions, as well as micropayments [47].

Overall, based on the aforementioned characteristics and functions of the blockchain, we can categorize blockchain use cases into categories [11]:

1. In lightweight transactions, a blockchain shared ledger marketplace is deployed for the exchange and transaction of scarce assets among a limited number of peers.

2. Provenance tracking focuses on the trace of origin and movement of assets across the entire supply chain utilizing virtual or digitalized "certificates of authenticity".

3. In the use case of inter-organizational record keeping, blockchain is used as an authoritative final "transaction log" mechanism for recording and notarizing all types of data of high importance or financial meaning in a collective manner.

4. The use of multiparty integration is to record data in a jointly managed data record/ledger. The aim is to overcome friction while proving redundancy.

Taking an empirical observation of the blockchain use cases, in the telecommunication and wireless communication industry lightweight transaction use cases include e.g., network sharing and roaming, neutral hosting, network assets marketplace (edge cloud resources, network slices, spectrum), Data-as-a-Service (DaaS) marketplace, network function virtualization (NFV) and software-defined network (SDN) transaction-based networking and services. Provenance tracking can benefit system tests, certification, and integrity checking related to operations security (OPSEC), supply chain and asset tracking, and Identity-asa-Service for Internet-of-Things (IoT) machines. Furthermore, inter-organizational record keeping and multiparty integration related use cases stem from audit trail of critical inter-network element data exchange, performance monitoring and fault detection, and official registry for government licensed assets, certified elements, and rules databases.

\subsection{Blockchain and the smart grid architecture model}

According to [48], a smart grid is an electricity network that can incorporate in a cost-efficient manner the behavior and actions of all users connected to it (generators and consumers) in order to ensure an economically efficient, sustainable power system with a high level of quality and security of supply and safety. "It is reasonable to view [the Smart Grid] as an evolution of the current grid to take into account new requirements, to develop new applications and to integrate new state-of-the-art technologies, in particular, Information and Communication Technologies (ICT). Integration of ICT into smart grids will provide extended applications management capabilities over an integrated secure, reliable and high-performance network." [48].

It is suggested by [49] that the blockchain technology is poised to improve the smart grids that incorporate communication technology and sensors. This can range from super grids that connect large-scale energy systems (e.g., storage) to microgrids that are designed for connecting DERs. In order to systematically study the connection between the blockchain and the smart grid, we introduce a formal framework developed in the EU, namely the Smart Grid Architectural Model (SGAM). In 2011, the European Commission and the European Free Trade Association (EFTA) issued the Smart Grid Mandate M/490, which is 
accepted by the three European standards organizations: the European Committee for Standardization (CEN), the European Committee for Electrotechnical Standardization (CENELEC), and the European Telecommunications Standards Institute (ETSI). The mandate requests CEN, CENELEC, and ETSI to develop a framework and perform continuous standard enhancement and development in the smart grid field. In order to carry out the requested work effectively, the three standardization organizations combined their strategic approach and established the CENCENELEC-ETSI Smart Grid Coordination Group (SGCG). SG-CG is responsible for coordinating the Smart Grid Mandate M/490. A key outcome of the SG-CG's work is the creation and establishment of the SGAM.

The development of the SGAM is based on NIST Framework and Roadmap for Smart Grid Interoperability Standards [50]. According to [51], the U.S. National Institute of Standards and Testing (NIST) defines a hierarchical information network architecture where smart grid networks are categorized into three types [50]:

1. A Home Area Network (HAN): focusing on the indoor or small-scale data communication between home appliances or energy systems in household settings.

2. A Neighborhood Area Network (NAN): supporting a backbone infrastructure to transport data from multiple HANs.

3. A Wide Area Network (WAN): providing a wide area backbone that has high capacity and reliability for large data transfers from multiple HANs within a smart grid network.

The SGMA is then adapting to the EU context and integrating the DERs into the framework. As [52] report, the SGAM has rapidly proven to be one of the key applicable methodologies to deal with the modeling and discussion of emerging technologies in the smart grids domain.

Referring to [48], the SGAM (Fig. 1) adopts a multilayer architecture. Such an architectural approach has been utilized in different smart grid studies. For instance, [53] develop and propose a multilayer architecture for a smart distribution grid with the focus on microgrids. The SGAM framework consists of five layers, representing business objectives and processes, functions, information exchange and data models, communication protocols, and components. Each layer in the SGAM covers the smart grid plane, which is spanned by electrical and ICT domains. The objective of this model is to represent and classify in which zones of information management interactions between domains take place. It allows for the presentation of the current state of implementations in the electrical grid, but further depicts the evolution of future smart grid scenarios by supporting the five key principles: universality, localization, consistency, flexibility, and interoperability. Moreover, the SGAM framework is established by incorporating the concept of interoperability layers defined in the smart grid plane. There are five interoperable layers of SGAM, namely the business layer, the function layer, the information layer, the communication layer, and the component layer. The following part explains how each layer is defined and blockchain's relevance to each layer.

Business layer The business layer represents the business view on the data and information exchange inside the smart grids. The SGAM can be used to map regulatory and market structures, business models, products and services, and involved energy market participants. In addition, business capabilities and business processes can be represented in this layer. In this way, the layer supports utility and telecom business executives in decision-making related to the existing and new business models and business projects (or business case) as well as regulators in defining new market models. The layer is particularly important for a blockchain since the layer can define and depict where the blockchain can enable a decentralized and distributed energy marketplace, introducing new business models and market models. On the other hand, the policy and regulation issues are visible and presented here. For example, in terms of market access in the EU, smaller prosumers seem to lack the ability to trade and participate directly in local and national energy markets due to existing regulatory barriers on the threshold of renewable self-consumers. This will create a barrier for prosumer-driven business models and market design that can be supported by the blockchain technology.

Function layer The function layer specifies the functions and services within the smart grids. It is necessary to note that the functions are described as being independent of the actors and physical implementations in the smart grids in this layer. The functions are developed according to the use case functionality requirements. Thus, the function layer is not directly related to the blockchain in most of the current smart grid functionalities and applications. However, when the use cases of the decentralized energy market become a focal point, certain functionality of the blockchain may become relevant in this layer.

Information layer The information layer of the SGAM describes the information that is being used and exchanged between functions, services, and components in the smart grids. The core of this layer is to define the information objects and data models, which in turn creates the common semantics for smart grid services and applications to have an interoperable information exchange via communications. According to [54], blockchain technologies all contain a Block, a Block header, and Transactions. However, different blockchain technologies may not adopt the same information objects and data model. The original bitcoin 


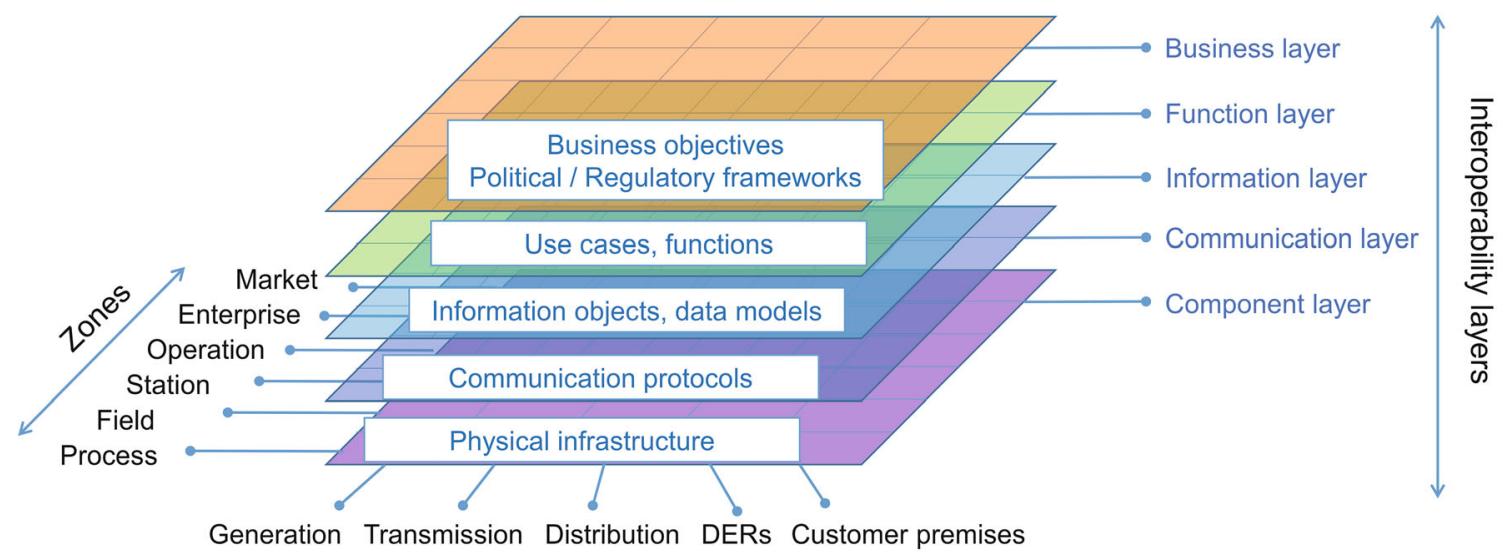

Domains

Fig. 1 The smart grid architecture model (SGAM) (Adapted from [48])

uses the proof-of-work (PoW) system that adopts UTXOs (unspent transaction outputs) to track and validate the transaction state. Essentially, it is a collection of all the bitcoins that have been created and not yet spent, with each UTXO having a denomination and an owner (defined by a cryptographic public key). The transaction of a UTXO contains one or multiple inputs, where each input has a reference to an existing UTXO and a cryptographic signature produced by the private key of the bitcoin owner and one or multiple outputs consisting of a new UTXO to be added to the state [55]. In addition to PoW and UTXO, new data models for the blockchain are emerging, for instance, Ethereum [56] is a mainstream blockchain platform (adopted in numerous smart grid pilots and applications) that relies on the state replication approach where each new block's state is the transaction result that is incorporated in the block through an account-based model and smart contracts. Basically, each account in the blockchain experiences direct value and information transfers with state transitions [57]. Overall, this shows that the SGAM's information layer is relevant to the blockchain where the data models are concerned. The design of this layer is related to the functionalities determined and required in the function layer on top of it.

Communication layer The focus of the communication layer is to describe communication protocols and mechanisms for the interoperable exchange of information between components in the context of the business case defined in the business layer, function specifications, and the relevant information objects or data models. If the blockchain changes the business or market model and has a different data model than the legacy systems, there can be an impact on the choice of communication protocols as well.
Component layer At last, the component layer is at the bottom of the SGAM, which is the physical distribution of all participating components in the smart grids. For instance, this layer includes the power system equipment, protection and control devices, network infrastructure, and computation infrastructure. Since the blockchain technology is normally enabled by a software platform, the component layer can be seen as a physical and infrastructural enabler, providing the computation, storage and communication infrastructure, and resources for the deployment of the blockchain.

\subsection{The blockchain's applications in smart grids}

The SGAM's business layer is particularly important for a blockchain since the layer can define and depict where the blockchain can enable a decentralized and distributed energy marketplace, introducing new business models and market models. A number of blockchain energy initiatives are emerging globally, such as the Brooklyn Microgrid which is built on the Ethereum blockchain platform $[58,59]$. The antecedents of blockchain-enabled electricity trading and marketplaces can be found in both the conceptual realm (e.g. [36]) and empirical domains, such as smart energy and blockchain entrepreneurs and startups (e.g. [60]). For instance, P2P energy trading is one of the highly promising domains for the blockchain marketplace $[36,58,61]$. At the conceptual level, a case of decentralized sharing in photovoltaic (PV) generation is proposed by [49]. The conceptual use case investigates the autonomous optimization and energy trading among different systems (including heating, cooling, hot water storage, and energy storage), which resembles a localized machine-to-machine electricity market. Empirically, smart energy startups such as Dajie have conducted a blockchain market pilot in 
reality with the aim of using the blockchain to facilitate the high volume and complexity of financial transactions arising from integrating IoT (Internet of Things) devices in a microgrid [60].

Through researching the existing use cases of a blockchain in the energy sector, the results show that blockchain applications for smart grids can be classified into four categories: Innovative solutions for $\mathrm{H} 2 \mathrm{H}$ (human to human) trading, $\mathrm{M} 2 \mathrm{H}$ (machine to human) trading, and M2M (machine to machine) trading. It is suggested by [62] that the use of blockchain technology for electricity transactions makes microgrids more resilient by creating trust between the involved agents, especially with respect to financial payments and electricity delivery.

Peer energy trading is one of the most promising potential areas for the application of blockchain [58]. This paper identifies $\mathrm{H} 2 \mathrm{H}$ trading applications such as community energy markets. The Brooklyn Microgrid is an empirical example where household residents trade energy among themselves. This blockchain platform provides the technical infrastructure for the local electricity market. Prosumers and consumers can submit, buy, and sell electricity orders to the market through a pre-defined market mechanism [58].

Regarding $\mathrm{M} 2 \mathrm{H}$ trading, GrünStromJeton is another case studied in the European Commission's report [63]. GrünStromJeton provides an index that indicates the relative production of energy from alternative renewables during the next $36 \mathrm{~h}$. The system monitors and records the energy consumption of the customers and rewards consumers when they use renewable energy sources. This is a trading mechanism between GrünStromJeton's digital system and actual consumers.

In terms of M2M trading, sharing photovoltaic (PV) generation is a case proposed by [49]. In this case, a typical family house of this community would be equipped with a PV system, a heat pump, a hot water storage system, and multiple sensors. The described concept application intends to identify the technically possible optimal usage of different systems (heating, cooling, hot water storage, ESS) in combination with short-term weather forecasts and energy consumption prediction driven by machine learning.

Overall, the use cases and business model discussion of the blockchain are well connected with the SGAM's business layer, which is visible in numerous blockchain publications [30-34], although not specifically stated. In addition to the business layer, stemming from a shared ledger lightweight transaction marketplace, blockchain technologies can be utilized in the underpinning layers of the SGAM, contributing to use cases related to provenance tracking, inter-organizational record keeping, and multiparty integration. However, only a few papers have provided insight into how the blockchain and blockchain business model archetypes are related to the other layers of the SGAM. Thus, this study will expand the existing blockchain literature with a closer discussion of the SGAM as a formal framework and architecture of smart grids.

\section{Research methodology}

This research utilizes an action research methodology that has been applied in the domain of techno-social research [64-66]. The study is part of an EU energy innovation research with the focus on the large-scale P2P energy trading in smart grids that is made possible by a decentralized energy market design as well as the enabling ICT technologies. The action research approach has been utilized in various domains for creating new scientific insight and findings that can be used to guide or support empirical actions [67]. In particular, the action approach is able to help form and contextualize the conceptual models and tools, constructing new knowledge [68].

The study involves two phases or stages: in the first phase, the study follows a systematic analysis of four business model archetypes through the value configuration approach of the business model, as well as through the interpretive case study approach [69-71]. After that, the four generic business model archetypes and their value configuration/architecture in the electricity market are applied and analyzed. In the second stage, the study takes an action-oriented approach $([67,72])$ to go beyond the conventional descriptive analysis of business model studies. With the participation of academic researchers and an industry practitioner of this research, the study constructs the blockchain marketplace as a new business model archetype and market design for future smart grids. In sum, the study analyzes energy and blockchain business cases in the first stage and utilizes the action research approach to construct the blockchain marketplace in the second stage.

More specifically, in the initial phase, the study conducts an investigation of 51 innovative cases of energy business models in different smart grid domains (including blockchain cases). The researchers collected the data from the European Commission (EC)'s BRIDGE program that focuses on building cooperation among more than 30 European smart grid and energy innovation projects. The business model cases are collected as smart grid business example, cases and archetypes in the electricity market, which is similar to [6] 's energy business model archetypes. To minimize the common selection bias [73], all cases of the research are contributed by the stakeholders in the energy ecosystem, for instance, the large and small energy firms and business practitioners, industry experts, policymakers as well as researchers from the scientific community. The collection of the major business model cases and 
archetypes enables an extensive analysis of the existing and emerging business model archetypes in the smart energy industry.

The second phase focuses on re-configuring the existing business models and the forms of value creation and capture with the aim of developing the new business model and value architecture for the decentralized energy market. The study builds on [28] 's business model configuration approach for digital businesses as it is relevant to the context of smart grid digitalization. Furthermore, a systemic and value-centric perspective for the value configuration/architecture of the business model is utilized, which included the needs $(\mathrm{N})$, the resources $(\mathrm{R})$, and the created value (V-C) of all value co-creators within the smart grid ecosystem. This design and architectural development approach is grounded in the literature of resource orchestration [25] and business model design [74].

\section{The fully decentralized business model configuration/architecture for the electricity market}

This section presents the research results on the new decentralized business model architecture for the energy market, covering four existing orchestrator-led business model archetypes and the fifth orchestrator-free architecture/configuration suggested by this research.

\subsection{The four archetypes of orchestrator-driven business models}

The four archetypes of orchestrator-driven business models in the electricity market are presented in this section (Fig. 2).

Archetype A: the utility centralization model The centralization model depicts the business model of conventional energy firms. This archetype is similar to the "firm as an integrator" model, which has a simple value configuration: a fully integrated or centralized utility (orchestrator) manages the entire process of generation, converting the generation fuel as input resources $\left(\mathrm{R}_{\mathrm{UC}}\right)$ into consumable energy that satisfies the end user's energy consumption need $\left(\mathrm{N}_{1}\right)$. End users then contribute to the financial need of the utility firms $\left(\mathrm{N}_{\mathrm{UC}}\right)$ in the monetary form, such as the payment for an electricity bill $\left(\mathrm{R}_{1}\right)$. The Archetype A is a supply-focused business model [14], focusing on transforming material supply into value. According to [6], this conventional and centralized business model architecture makes very little space for the growth of DERs, giving a poor performance (value creation) for local-oriented energy efficiency.

Archetype B: the unbundled retailer model Unbundled retailers are normally found in countries with a high degree of energy market liberalization. Referring to [6], an unbundled retailer does not own generation assets, for instance, power plants. The unbundled retailer would cooperate with energy generators (or acquire energy supply from the wholesale energy market) and labeling the energy with its own brand. The value configuration/architecture of this business model shows that the unbundled retailer cocreates value with generation asset owners $\left(\mathrm{V}-\mathrm{C}_{2}\right)$ to provide energy and diverse service to meet the consumers' needs $\left(\mathrm{N}_{1}\right)$. The unbundled retailer incorporates the resources of its own and partners' $\left(R_{U R}\right.$ and $\left.R_{2}\right)$. Therefore, Archetype $\mathrm{B}$ is not about material transformation, rather a collaborator who engages with its value "complementors" $\left(\mathrm{V}-\mathrm{C}_{2}\right)$ [27] to create value for end users $\left(\mathrm{V}-\mathrm{C}_{1}\right)$. Archetype $\mathrm{B}$ can be considered as a demand-focused business mode [14].

Archetype C: the platform model The utilization of the platform business model in the energy market is introduced by [75]. This archetype emphasizes the role of a new actor in the energy ecosystem, namely the platform operator who
Fig. 2 The four archetypes of business models in the energy market
Archetype A: The utility centralization model

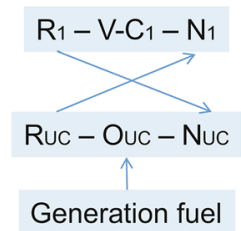

Archetype B: The unbundled retailer model

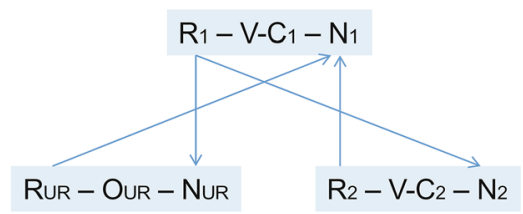

Archetype C: The platform model

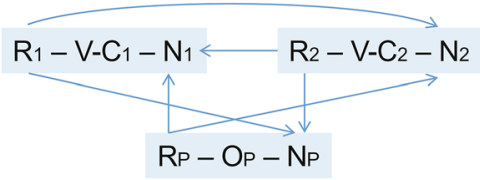

Archetype D: The balancing operator model

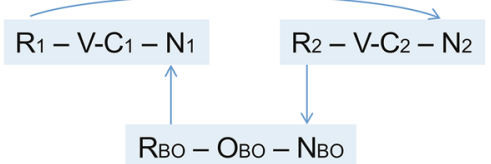


brings together producers and consumers of products and services, creating value by interaction facilitation and matchmaking. The network effect or network externality rises from a platform marketplace, which means the value created by the platform changes in regard to the participation rates on the same side and the cross side [75]. In the energy market, the platform operator creates value by mediating the interactions and matching between groups of end users and value co-creators. One example is the electricity trading between consumers and prosumers or consumers and suppliers whose needs $\left(\mathrm{N}_{1}\right.$ and $\left.\mathrm{N}_{2}\right)$ are matched by each other's resources $\left(\mathrm{R}_{2}\right.$ and $\left.\mathrm{R}_{1}\right)$.

Archetype D: the balancing operator model According to [76], electricity balancing is defined as the institutional arrangement that creates market-based balance management in liberalized electricity markets. A business model example of the balancing operator archetype is the virtual power plant (VPP) [68]. In Archetype D, the value architecture is as follow: a balancing operator meets the needs $\left(\mathrm{N}_{1}\right.$, such as energy efficiency service) of the end users or consumers by deploying its resources $\left(\mathrm{R}_{\mathrm{BO}}\right)$. At the same time, the balancing operator collects consumption data and implements machine learning and artificial intelligence algorithms to discover the consumption patterns of the consumer $\left(\mathrm{R}_{1}\right)$ as a new resource to create value for the need of another group, usually the distribution network operators (DSOs) $\left(\mathrm{N}_{2}\right)$. The Archetype D is unique in the way that the balancing operator leverages the data from one group of customers to create value for another customer group.

\subsection{The blockchain marketplace as the fifth business model archetype}

Based on the above discussion, we propose the simplest form of the blockchain-enabled marketplace for a fully decentralized energy market without the need of an orchestrator (Fig. 3).

Referring to the previous section, blockchain and smart contracts can enable peer-driven (P2P) digital transaction, establishing decentralized architecture for market-based energy trading. For instance, the value configuration/

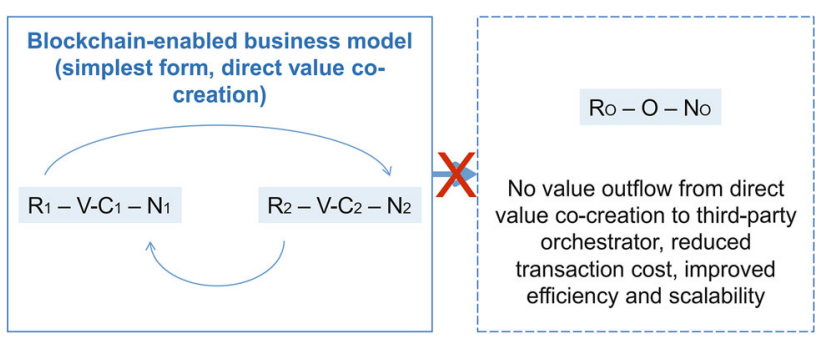

Fig. 3 The simplest form of a blockchain-enabled marketplace architecture of a blockchain-enabled energy and flexibility trading can be that market participant 1 can match its $\mathrm{N}_{1}$ with the $R_{2}$ of market participant 2 (such as the case of), while the $R_{1}$ as financial value is directed to $N_{2}$ without a meditating entity blocking the direct value co-creation and co-capture.

From a technical perspective, a blockchain-enabled digital marketplace can deploy blockchain as a chronological, immutable, and trusted data storage, while the smart contracts can automate offer testing and modification based on the parameters tuned in the feedback loop. Essentially, it is argued that transaction costs are strongly related to the distrust among market participants in a transaction [77]. The blockchain as an enabling technology can empower the process of crowdsourced resource pooling by lowering transaction costs in terms of verification and networking [41]. At the same time, the utilization of smart contracts can automate other processes associated with a typical transaction, such as negotiation, establishment, and enforcement. Blockchain can provide trusted data for prospecting and sorting algorithms that can further improve the operational and business processes for the energy market. Currently, new and secure encryption methods are being developed (e.g. [78, 79]) to mitigate the privacy risk concerning the substantial data generated by blockchain.

In this way, blockchain allows the transaction side of value creation and capture to operate on autopilot, and further enables digitalized value architecture for needs and resource matching. In sum, the blockchain marketplace is expected to automate large volume of decentralized transactions, enabling direct value creation, value capture and value sharing flows, cutting transaction costs, and achieving improved market efficiency in contrast to a centralized business model architecture (Fig. 4). Theoretically, there is no value outflow in the direct value creation and capture process in the blockchain marketplace, which creates a bigger value share for market participants.

From the business model and market design perspective, the blockchain enables the unique grafting of resource combinations and the novel value configuration and architecture of the business model in the energy market. Moreover, by tuning the smart contract parameters defining the roles of participants in the energy market, the blockchain marketplace can enhance the complementarity in the grafting process of value creation, capture and sharing.

Our study acknowledges the contribution from previous studies (e.g. [36]) and extends the research on two fronts: (1) this research focuses on the ecosystem archetype of the electricity market and ecosystem, which is similar to the combination of the P2P energy trading and flexibility trading platforms in [36]. This study enriches our understanding of such blockchain-enabled businesses from the 


\section{Orchestrator-driven energy market (from centralization to pseudo-decentralization)}

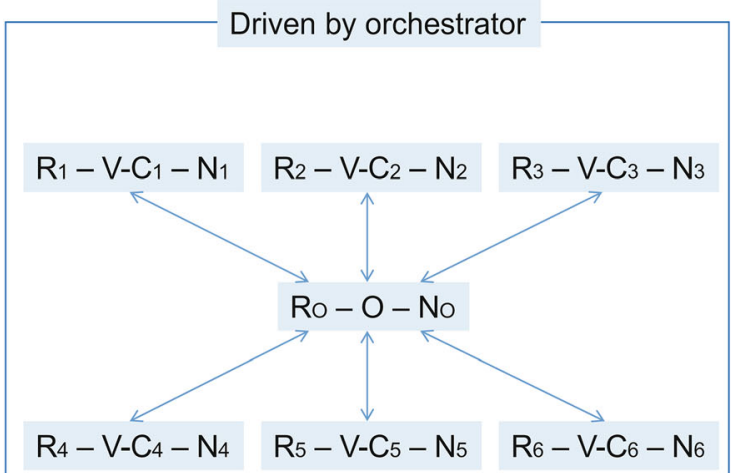

The fifth energy market: The blockchain marketplace (full decentralization)

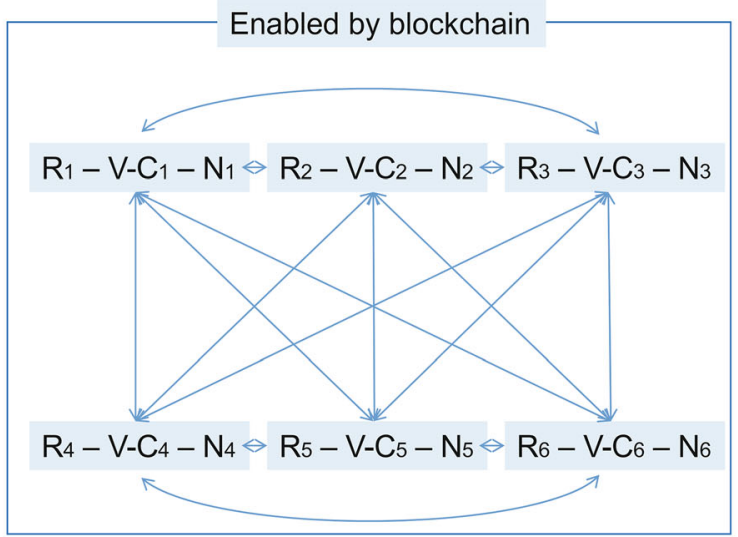

Ro $-\mathrm{O}-$ No Orchestrator $\mathrm{Rx}-\mathrm{V}-\mathrm{Cx}-\mathrm{N} x$ Market participant

Value co-creation flow

Fig. 4 Comparing the orchestrator-driven energy market and the blockchain marketplace

descriptive level-the "what?" to the "how?"-of the value configuration approach to explaining how such a platform can be created or formed. In other words, this research does not only give a description of the new business model archetype at narrative and ontological levels of abstraction but also presents a more detailed discussion on how such a business model archetype works, building on the meta model of [29]. (2) The traditional P2P trading platform is still considered the orchestrator platform or pseudo-orchestrator platform from which the platform operators can extract a significant level of value from the platform. This argument has already been provided by [31] for businesses in other industries, for example, Amazon and AirBnB. This study's proposition for the blockchain marketplace is that it is an orchestratorfree platform with the aim of maximizing the shared value in the energy ecosystem without intermediary platform operators. As the study suggests that the conventional platform design is another way of intermediation, where the traditional "middle-man" type of intermediation is removed or substituted by the platform intermediation. In some cases, the platform operators can retain more resources and power in the ecosystem (e.g. Uber, Amazon) [31]. From the value perspective, one essential value proposition that the blockchain can bring is the disintermediation and maximization of ecosystem value, and the blockchain marketplace is in line with such a value proposition.

\subsection{Understanding the blockchain marketplace with the SGAM}

At the conceptual level, the blockchain marketplace is a market- and ecosystem-level business model which is highly relevant to the business layer of the SGAM. However, further investigation shows that this archetype is connected with other layers of the SGAM through a modularized value proposition that can be configured.

In the case of P2P energy trading-especially starting from the local grid, where energy is produced and consumed in a limited geographical area, such as a local neighborhood (e.g. a local energy community)—one major problem that arises from the existing business layer is related to market design and regulations that limit the incentive for small-scale prosumers to participate in the energy market. Market aggregators emerge to address the need by aggregating energy consumption or/and flexibility as a business model. Furthermore, utility companies act as middle-men to address the need for selling the renewable production surplus from the small-scale prosumers at a price that is relatively beneficial to the utility, for example, the buying price given to the prosumers may be lower than the market price, depending on the country and region. As a new business model archetype, the blockchain marketplace will make it possible for micro-grid and small-scale prosumers and consumers to generate, store, trade or share energy and flexibility without conventional barriers, in other words, directly matching $\mathrm{N}_{1}$ (the need of market participant/peer (1) with $R_{2}$ (the resource of market participant/peer (2) and transferring the $\mathrm{R}_{1}$ (financial payment of market participant/peer (1) to $\mathrm{N}_{2}$ (payback need of market participant/peer (2) without intermediation. As 
previously mentioned, the study envisions the use of a blockchain system with the support of smart contracts to provide decentralized transactions and clearing with lower costs to the parties in trading.

Moreover, taking the new application/use case of electric mobility as an example, the blockchain marketplace can allow electric mobility to be integrated into decentralized energy systems. Here, the blockchain marketplace can be a domain-specific model for the charging of EVs, payment enablement and asset/fleet management. The strength of the blockchain is its application in situations where the provenance of an asset and the data from it both need to be interrogated and updated by multiple parties.

On the function layer, the blockchain marketplace can improve and transform the conventional way of arranging, recording and verifying energy transactions, underpinning the shift away from a centralized structure with orchestrators (such as exchanges, trading platforms, and utility companies) towards disintermediated and decentralized systems where end consumers/prosumers interact directly. With a centralized clearing house, energy exchange may be rendered less important or even obsolete. Today's intra-day and day-ahead markets, which only facilitate large-scale energy and flexibility transactions, can be expanded to enable more granular transitions such as those at the household level or potentially at the appliance level.

Regarding the functions for ancillary services, which transmission system operators (TSOs) and DSOs need for guaranteeing the dependability and security of electrical grids, these services include frequency control, voltage control, and congestion management. Access to the services offered by a broad range of providers-including DERs, renewable energy resources (RESs), aggregators and prosumers-will allow TSOs to make more efficient decisions in order to improve the reliability, availability, maintainability, safety, integrity, and security. Today, resources connected to a medium voltage (MV) grid cannot provide ancillary services. However, implementing smart grid functionalities, DSOs will be enabled to manage new elements and information from the network and, consequently, improve the real-time operations. Furthermore, there is a need to integrate DER providers offering technical aggregation services related to frequency and voltage control. There can be several different TSO-DSO-DER coordination schemes in relation to prequalification, procurement, activation and settlement processes depending on the stage of decentralization. A significant expansion of DER plants connected to the MV and low voltage (LV) networks will impact on the DSO's supervisory control and data acquisition (SCADA) system and create the need for enhancements in order to manage new devices and information coming from the network and the need for new applications to support the DSOs in real-time operation.
New forecast information from the DSOs to the TSOs is added related to network management and control, for example, the real power split by the DER, the real power of the disconnected DER, and the real power of the load. Here the blockchain technology can be utilized to provide interorganizational recordkeeping and integration. In performance monitoring and fault detection data, the blockchain offers timestamped, persistent and trusted process data storage that provides the data basis for analysis and sorting algorithms, and further artificial intelligence (AI)-based forecasting. The results of analyses can be used as parameters for the smart contract-based automated provision. The energy grid in general, as critical infrastructure, is governed at length and highly regulated. The blockchain marketplace can provide the authoritative final "transaction $\log$ " mechanism for collectively recording and notarizing aspects, for example, for monitoring and observing conditions, official registry for government licensed assets, certified elements, and rules databases. The real-time monitoring and analysis of energy use functions related to blockchain use cases include energy certification and verification, and offsetting $\mathrm{CO} 2$ emissions and rewarding sustainable measures. The blockchain marketplace and blockchain technology's benefits in the function layer include reduced costs, the elimination of data duplication, increased transaction speed and greater resilience.

The information layer describes the information that is being used and exchanged between functions, services, and elements. The blockchain marketplace is expected to change the existing transaction lifecycle. Taking smart metering infrastructure as an example of a blockchain opportunity in the lower layer of the SGAM. Smart grid metering consists of smart meter hardware and software, communication networks from smart meters to local data concentrators, back-haul from these aggregation points to utility data centers, a meter data management system (MDMS) and integration into back-office software application in the business layer. Smart metering extends the traditional DSO network to the prosumer/consumer's HAN, covering the following processes and related information data flows: collecting and sending usage data to the utility, receiving rating data and firmware updates from the utility, measuring grid feed-in from local distributed generation, activating and deactivating accounts, detecting power quality issues and outages, detecting tampering, offering advanced and time-of-day tariffs, profiling individual households for marketing and profiling aggregate household consumption. HAN elements generate data with high privacy and monetary value. Here the blockchain use case covers an Identity-as-a-Service authentication solution for HAN IoT elements and constitutes a pool of reliable, shared and confidential data with a permanent audit trail. As suggested by [35], a blockchain in permanent 
communication with these connected objects which uses smart contracts and Dapps/dApps (decentralized applications, according to $[35,80]$ ) could theoretically manage a local authority's energy infrastructure without direct human intervention.

The communication layer focuses on the interoperable exchange of mission- and business-critical information between elements in the context of the SGAM layers. The audit trail of critical communication with timestamps and proof of origin can be used in performance monitoring and fault detection. In the blockchain-enabled grid operations, organizations and architectural elements can have a shared view of the reality for business and operational processes. As this insight does not originate from a sole source, the blockchain solution can act as multiparty integrator within a grid. The development of an interoperating parallel blockchain using an inter-blockchain communication protocol paves the way for larger ecosystems with novel resource combinations.

The physical component layer will play an enabler role of the blockchain marketplace, in which the blockchain can integrate with existing control mechanisms and offer a space for novel control approaches to optimizing the distribution grids. Blockchain use cases mainly consist of provenance-tracking solutions to OPSEC, the software and hardware supply chain and asset tracking. These applications can benefit system testing, certification, and integrity checking across a wide variety of grid elements, such as actors, power system equipment, protection, and telecontrol devices, network infrastructure (wired/wireless communication connections, routers, switches, and servers) and computation infrastructure.

Furthermore, in a blockchain platform, the virtualization of the underlying hardware benefits from the reliable identification of elements and their permissions enabled via blockchain-based digital keys and identities. The introduction of the smart grid and blockchain will restructure business roles and hierarchies, as well as the responsibilities of stakeholders not covered by the current regulatory framework. For example, the basic definitions of actors, such as consumers or suppliers, may not be legally valid in blockchain-based establishment because of their centralized origins. Currently, in the case of supplier failure, consumers are legally protected; on the other hand, in the decentralized scenario with variable prosumers, measuring and enforcing accountability may be extremely complicated. The situation is further compounded by the ambiguous legal status of smart contracts in regard to the extent to which traditional contract law doctrines can be applied. The blockchain provides virtual "certificates of authenticity" that document asset ownership; an audit trail of critical inter-network element data exchange, performance monitoring and fault detection; and provide an official registry for governmental use.

Looking at the electric mobility case, the blockchain marketplace offers the possibility to enable electric mobility to be added to energy-system storage and demand-supply balancing. For instance, RWE (a large electric utility in Germany and Europe) has developed BlockCharge, a hardware-software integrated application that links to a blockchain-based network, allowing electric car owners to charge their cars via any charging station network and to be billed for the energy consumed [81]. The EVs interact automatically with the stations, and the electricity payment process is autonomous. This type of charging information can help increase the management and optimization of decentralized grid solutions.

\subsection{Further development of the blockchain marketplace as a new archetype}

On top of conceptualizing the blockchain marketplace as an orchestrator-free business model archetype, this paper also recognizes that remarkable challenges remain in the way of blockchain adoption and it offers insights and thoughts for the empirical implementation of the blockchain marketplace for further development.

Regarding the blockchain challenges, the general technological challenges that are often associated with the blockchain are scalability, throughput, transaction verification time and power consumption, as well as issues concerning privacy and security [45]. From the energy ecosystem perspective, it is suggested by [82] that the basic definitions of actors (e.g. consumers or suppliers) in conventional smart grids will not be legally valid in blockchain-based establishments because of their centralized origins. Instead of trying to define clear-cut roles for actors, [82] argues that regulating dispersed responsibilities in a decentralized blockchain environment should solely focus on the quantity and the quality functions of energy supply and especially on finding mechanisms for pooling responsibilities. From the legal perspective, as argued by [83], the extent to which traditional contract law doctrines can be applied to smart contracts is still unclear and probably factual solutions will, in the future, only be found through practice.

A further challenge for the blockchain market is associated with the energy market regulation, which can be seen as a limiting factor or a barrier for the adoption of such a business model. However, the regulatory environment could potentially be improved and developed in a favorable direction towards a more decentralized energy market. For instance, the Finnish Smart Grid Working Group [84] has proposed to better enable the energy community, such as eliminating the distribution fees and 
taxes for energy generated and consumed by the energy communities within housing companies. Complementary to this, a blockchain platform for digitalization of the housing trade is also under development in Finland [85], which can stimulate the policy discussion on a more decentralized and open market. Therefore, ongoing work is needed to study and monitor existing regulatory barriers for the use of blockchain by utilities, prosumers, and other stakeholders through various venues like the European Blockchain Observatory and Forum.

The adoption of the blockchain marketplace, especially the increased use of blockchain technology, can take processual steps. For example, the blockchain may become a component of current energy and electricity systems. It may replace a certain sub-system (or sub-systems) first and gradually reach all of the current systems, or it may become a separate system which will stay alongside the current systems as an alternative. Specifically, the study of [86] suggests that considerations can be focused on how the blockchain platform can be smoothly integrated with legacy enterprise systems and IoT platforms. For instance, how previous transactions will be imported into the blockchain or, in the case of a complete system substitution, how the existing system can be progressively replaced, retaining the possibility to return to the previous system combination if integration issues occur.

One potential development of the blockchain marketplace is the formation of a crypto stack [61] that can be integrated into the SGAM. This study suggests that the increasing development and deployment of blockchain technology in different layers of the SGAM can form an infrastructure-like layer or dimension, namely the crypto stack. The crypto stack can serve as an enabling foundation or base for the technology developers and engineers to create more and more decentralized applications or dApps for the energy industry. In this paper, we believe that by using the blockchain marketplace as a new business model archetype or paradigm of designing the energy market, combining the blockchain and the existing smart grid functionalities in one layer or multiple layers of the SGAM, new value propositions and novel ways of value creation and capture can spring up from areas-such as from technical architecture design and development, energy service and use case creation, and business model configuration and development-eventually facilitating and benefiting a decentralized energy ecosystem.

\section{Conclusions and implications}

By adopting the value configuration and architecture perspective, this research proposes the fully decentralized business model archetype the electricity and energy market enabled by blockchain. The study identifies that the current electricity market design and business model follows a centralized scheme (or a pseudo-decentralization at its best), although the energy industry has invested significant effort for the energy market liberalization together with the transition from conventional grids to smart grids. This study suggests that the blockchain as a novel technology can have a profound effect on the energy market design, especially for the electricity market, but also potentially for other domains within the energy market. The outcomes are made possible by utilizing the value perspective of the business model to the current energy market research literature.

The research has the following theoretical implications: The study builds on the resource configuration approach for business model and extends to the value configuration/architecture view, suggesting that novel business model is not just about configuring the resources, but also transforming the architecture of how firms can create, capture and share value with the resources [25] [87]. Through examining the four up-to-date categories of business model archetypes [28] and 50 empirical business model cases, the study argues that the four archetypes are merely adequate to explain the orchestrator-driven business models, since an orchestrating entity is a pre-requisite for these business models to create value while extracting part of the value to meet the orchestrating entity's own needs in the form of revenue or profit.

To address this gap in the existing research and literature, we investigate the paradigm and the architecture of fully decentralized systems, such as the P2P network. As a result, the study proposes the blockchain marketplace as a fifth business model archetype for the energy market. It is identified as the sole archetype without the need of an orchestrator and a promising business model and market design to give the full autonomy to the energy market participants. The theoretical contribution of the study does not only contribute to scholarly discussion and debate on energy and electricity market design, but also introducing the system-oriented architectural thinking to management and organization studies, showing that business model and its value architecture can explain how resources are configured, how value is created, and how market needs are satisfied. With the re-configuration and transformation of the architecture, a fully decentralized energy market can be realized without the presence of an orchestrating firm or market entity. A novel business model at an ecosystem level can be formulated from an orchestrator-led energy market to a decentralized peer energy market enabled through blockchain.

The practical implications of the study are related to the identification of blockchain as an enabling technology for the decentralized and distributed operations of P2P energy 
market, changing the centralized legacy systems with the capability of enabling microgrids, DERs, renewable integration, $\mathrm{P} 2 \mathrm{P}$ energy trading and higher consumer/prosumer engagement through autonomous transactions and smart contract enforcement. The new capabilities brought forward by the blockchain will demand the energy industry to re-think not just value creation and capture, but also value sharing and even more novel systemic architecture for the energy and electricity market in the future.

One limitation of the study is that the research is more focused on the proposition and conceptualization of what a fully decentralized P2P energy market may be, such as the blockchain marketplace as a new business model archetype. It is key to note that this research remains critical about blockchain's true technical capability in enabling a decentralized energy system. Although the study envisions that the blockchain marketplace can draw a meaningful architecture design for the digitalized energy industry, we acknowledge that blockchain alone cannot solve all the issues and complexity in the energy system. Therefore, we recommend that future studies can have more extensive validation on the blockchain marketplace business models as well as other P2P business models in the energy industry. Further researchers can focus on comparing and verifying the effects and the performative aspects of the blockchain in P2P marketplace with quantitative approaches, for instance, using simulation and experimentation to evaluate the technical feasibility and limitation of the blockchain in the context of the P2P energy market.

Acknowledgements Open access funding provided by University of Oulu including Oulu University Hospital.

Open Access This article is distributed under the terms of the Creative Commons Attribution 4.0 International License (http://creative commons.org/licenses/by/4.0/), which permits unrestricted use, distribution, and reproduction in any medium, provided you give appropriate credit to the original author(s) and the source, provide a link to the Creative Commons license, and indicate if changes were made.

\section{References}

1. Mohamed, M. A., Eltamaly, A. M., Farh, H. M., \& Alolah, A. I. (2015). Energy management and renewable energy integration in smart grid system. In IEEE international conference on smart energy grid engineering (SEGE) (pp. 1-6). https://doi.org/10. $1109 /$ sege.2015.7324621

2. Nistor, S., Wu, J., Sooriyabandara, M., \& Ekanayake, J. (2015). Capability of smart appliances to provide reserve services. Applied Energy, 138, 590-597. https://doi.org/10.1016/j.apenergy. 2014.09.011.

3. Wang, J., Conejo, A. J., Wang, C., \& Yan, J. (2012). Smart grids, renewable energy integration, and climate change mitigationFuture electric energy systems. Applied Energy, 96, 1-3. https:// doi.org/10.1016/j.apenergy.2012.03.014.
4. Hasse, F., von Perfall, A., Hillebrand, T., Smole, E., Lay, L., \& Charlet, M. (2016). Blockchain-An opportunity for energy producers and consumers? PwC global power and utilities. Retrieved from www.pwc.com/utilities. Accessed 11 Nov 2017.

5. Palensky, P., Member, S., Dietrich, D., \& Member, S. (2011). Demand side management: Demand response. Intelligent Energy Systems, and Smart Loads, 7(3), 381-388.

6. Hall, S., \& Roelich, K. (2016). Business model innovation in electricity supply markets: The role of complex value in the United Kingdom. Energy Policy, 92, 286-298. https://doi.org/10. 1016/j.enpol.2016.02.019.

7. Xu, Y., Ahokangas, P., \& Reuter, E. (2017). EaaS: Electricity as a service? In 24th Nordic Academy of Management conference (pp. 1-22). Bodø: NFF.

8. European Commission. (2016). Clean energy for all Europeans. Brussels: DG ENER, The European Commission.

9. Nakamoto, S. (2008). Bitcoin: A peer-to-peer electronic cash system. https://bitcoin.org/bitcoin.pdf.

10. Antonopoulos, A. M. (2014). Mastering bitcoin: Unlocking digital cryptocurrencies. Journal of World Trade (1st edn., Vol. 50). Sebastopol, CA, USA: O'Reilly Media, Inc. https://doi.org/10. 1002/ejoc.201200111.

11. Yrjölä, S. (2017). Analysis of blockchain use cases in the Citizens Broadband Radio Service spectrum sharing concept. In 12th EAI international conference on cognitive radio oriented wireless networks, Lisbon.

12. Zhang, Y., \& Wen, J. (2017). The IoT electric business model: Using blockchain technology for the internet of things. Peer-toPeer Networking and Applications, 10(4), 983-994. https://doi. org/10.1007/s12083-016-0456-1.

13. Basden, J., \& Cottrell, M. (2017). How utilities are using blockchain to modernize the grid. Harvard Business Review, 2-5. Retrieved from http://search.ebscohost.com/login.aspx?direct= true $\& d b=b$ th $\& A N=122087645 \&$ lang=pt-br\&site=eds-live $\&$ auth type=uid. Accessed 11 Nov 2017.

14. Massa, L., Tucci, C. L., \& Afuah, A. (2016). A critical assessment of business model research. Academy of Management Annals, 11(1), 73-104. https://doi.org/10.5465/annals.2014.0072.

15. Demil, B., \& Lecocq, X. (2010). Business model evolution: In search of dynamic consistency. Long Range Planning, 43(2-3), 227-246. https://doi.org/10.1016/j.lrp.2010.02.004.

16. Johnson, M., Christensen, C. M., \& Kagermann, H. (2008). Reinventing your business model. Harvard Business Review, (December), 50-60. https://doi.org/10.1111/j.0955-6419.2005. 00347.x

17. Osterwalder, A., \& Pigneur, Y. (2010). Business model generation: A handbook for visionaries, game changers, and challengers. A handbook for visionaries, game changers, and challengers. Hoboken, New Jersey: Wiley. https://doi.org/10. 1523/jneurosci.0307-10.2010.

18. Chesbrough, H. (2010). Business model innovation: Opportunities and barriers. Long Range Planning, 43(2-3), 354-363. https://doi.org/10.1016/j.lrp.2009.07.010.

19. Zott, C., \& Amit, R. (2013). The business model: A theoretically anchored robust construct for strategic analysis. Strategic Organization, 11(4), 403-411. https://doi.org/10.1177/ 1476127013510466.

20. Afuah, A. (2014). Business model innovation: Concepts, analysis and cases. New York: Routledge. https://doi.org/10.1007/978-3319-53351-3.

21. Zott, C., \& Amit, R. (2010). Business model design: An activity system perspective. Long Range Planning, 43(2-3), 216-226. https://doi.org/10.1016/j.lrp.2009.07.004.

22. Zott, Christoph, \& Amit, R. (2008). The fit between product market strategy and business model: Implications for firm 
performance. Academy of Management Journal, 51(2), 315-334. https://doi.org/10.1002/smj.

23. Mazhelis, A., \& Mazhelis, O. (2012). Software business. Icsob, 114(May 2016), 261-266. https://doi.org/10.1007/978-3-64230746-1.

24. Brandenburger, A. M., \& Stuart, H. W. J. (1996). Value based business strategy. Journal of Economics \& Management Strategy, 5(1), 5-24. https://doi.org/10.1111/j.1430-9134.1996.00005.x.

25. Sirmon, D. G., Hitt, M. A., Ireland, R. D., \& Gilbert, B. A. (2011). Resource orchestration to create competitive advantage. Journal of Management, 37(5), 1390-1412. https://doi.org/10. $1177 / 0149206310385695$.

26. Wassmer, U., \& Dussauge, P. (2012). Network resource stocks and flows: How do alliance portfolios affect the value of new alliance formations? Strategic Management Journal, 33(7), 871-883. https://doi.org/10.1002/smj.

27. Adner, R., \& Kapoor, R. (2010). Value creation in innovation ecosystems: How the structure of technological interdependence affects firm performance in new technology generations. Strategic Management Journal, 31, 306-333. https://doi.org/10.1002/ smj.

28. Amit, R., \& Han, X. (2017). Value creation through novel resource configurations in a digitally enabled world. Strategic Entrepreneurship Journal, 11(3), 228-242. https://doi.org/10. 1002/sej.1256.

29. Massa, L., \& Tucci, C. L. (2014). Business model innovation. Oxford Handbook of Innovation Management, 2, 43. https://doi. org/10.1093/oxfordhb/9780199694945.013.002.

30. Momo, F., Schiavi, G., \& Behr, A. (2018). Business models and blockchain: What can change? In Proceedings of the 24th Americas conference on information systems (pp. 1-5). https:// doi.org/10.1109/tasc.2010.2099196.

31. Tumasjan, A., \& Beutel, T. (2019). Blockchain-based decentralized business models in the sharing economy: A technology adoption perspective. In H. Treiblmaier \& R. Beck (Eds.), Business transformation through blockchain. Cham: Palgrave Macmillan.

32. Kamal, H. T., \& Tayyab, S. (2017). The impact of blockchain on business models: A study on how the attributes of blockchain affect the elements of business model. Bergen: Norwegian School Of Economics.

33. Nowiński, W., \& Kozma, M. (2017). How can blockchain technology disrupt the existing business models? Entrepreneurial Business and Economics Review, 5(3), 173-188. https://doi.org/ 10.15678/EBER.2017.050309.

34. Asadi, L., \& Hoang, T. (2018). Blockchain how the implementation of blockchain is affected by, and affects, business models. University of Gothenburg. Retrieved from https://gupea.ub.gu.se/ bitstream/2077/57225/1/gupea_2077_57225_1.pdf. Accessed 3 Jan 2018.

35. Filipova, N. (2018). Blockchain-An opportunity for developing new business models. Svishtov, Bulgaria: Business Management, D.A.Tsenov Academy of Economics (No. 2, pp. 75-93).

36. Orlov, A. (2017). Blockchain in the electricity market: Identification and analysis of business models. Norwegian School of Economics \& HEC Paris. Norwegian School of Economics \& HEC Paris.

37. Botsman, R. (2013). The sharing economy lacks a shared definition. Fast Company. http://www.fastcoexist.com/3022028/thesharing-economy-lacks-a-shared-definition\#10. Accessed 27 Nov 2017.

38. Malhotra, A., \& Van Alstyne, M. (2014). The dark side of the sharing economy .... and how to lighten it. Communications of the ACM, 57(11), 24-27. https://doi.org/10.1145/2668893.

39. Botsman, R., \& Rogers, R. (2010). What's mine is yours-How collaborative consumption is changing the way we live (1st ed.).
New York: Harper Collins Inc. https://doi.org/10.1016/s01689525(00)00086-x.

40. Löbbers, J., von Hoffen, M., \& Becker, J. (2017). Business development in the sharing economy: A business model generation framework. In IEEE 19th conference on business informatics (CBI) (pp. 237-246). Thessaloniki: IEEE. https://doi.org/ 10.1109/cbi.2017.44.

41. Catalini, C., \& Gans, J. S. (2017). Some simple economics of the blockchain. SSRN Electronic Journal. https://doi.org/10.2139/ ssrn.2874598.

42. Vukolić, M. (2016). The quest for scalable blockchain fabric: Proof-of-work vs. BFT replication. In J. Camenisch \& D. Kesdoğan (Eds.), Open problems in network security iNetSec 2015 (Vol. 9591, pp. 112-125)., Lecture notes in computer science Cham: Springer. https://doi.org/10.1007/978-3-319-39028-4_9.

43. Kiayias, A., Russell, A., David, B., \& Oliynykov, R. (2016). A provably secure proof-of-stake blockchain protocol. IACR Cryptology. https://doi.org/10.1007/978-3-319-63688-7_12.

44. Christidis, K., \& Devetsikiotis, M. (2016). Blockchains and smart contracts for the Internet of Things. IEEE Access, 4, 2292-2303. https://doi.org/10.1109/ACCESS.2016.2566339.

45. Yli-Huumo, J., Ko, D., Choi, S., Park, S., \& Smolander, K. (2016). Where is current research on blockchain technology?-A systematic review. PLOS ONE, 11(10), 1-27. https://doi.org/10. 1371/journal.pone.0163477.

46. Szabo, N. (1994). Smart contracts. Retrieved March 22, 2018, from https://archive.is/X31R2. Accessed 26 Mar 2018.

47. Baliga, A. (2016). The blockchain landscape office of the CTO. Persistent Systems Ltd. https://pdfs.semanticscholar.org/c826/ b333dfb04e3053a7c2cb3b881bff1d952942.pdf.

48. CEN/CENELEC/ETSI. (2012). CEN-CENELEC-ETSI Smart Grid Coordination Group: Smart grid information security. Brussels. Retrieved from ftp://ftp.cen.eu/EN/European Standardization/HotTopics/SmartGrids/Security.pdf. Accessed 27 June 2018.

49. Meisel, M., Fotiadis, L., Wilker, S., Treytl, A., \& Sauter, T. (2017). Blockchain applications in microgrids: An overview of current projects and concepts Andrija. In IECON 2017-43rd annual conference of the IEEE industrial electronics society (pp. 6153-6158). https://doi.org/10.1109/iecon.2017.8217069.

50. Bryson, J., \& Gallagher, P. D. (2012). NIST framework and roadmap for smart grid interoperability standards, release 2.0. NIST special publication $1108 R 2$ (Vol. 0). https://doi.org/10. 6028/nist.sp.1108r3.

51. Kim, J., Han, J., Mir, Z. H., \& Ko, Y. B. (2017). Efficient topology construction and routing for IEEE $802.15 .4 \mathrm{~m}$-based smart grid networks. Wireless Networks, 23(2), 533-551. https:// doi.org/10.1007/s11276-015-1164-0.

52. Trefke, J., Rohjans, S., Uslar, M., Lehnhoff, S., Nordström, L., \& Saleem, A. (2013). Smart grid architecture model use case management in a large European smart grid project. 4th IEEE PES innovative smart grid technologies Europe. https://doi.org/ 10.1109/isgteurope.2013.6695266.

53. Devidas, A. R., Ramesh, M. V., \& Rangan, V. P. (2018). High performance communication architecture for smart distribution power grid in developing nations. Wireless Networks, 24, 1621-1638. https://doi.org/10.1007/s11276-016-1400-2.

54. Ellervee, A., Matulevicius, R., \& Mayer, N. (2017). A comprehensive reference model for blockchain-based distributed ledger technology. CEUR Workshop Proceedings, 1979, 320-333.

55. Buterin, V. (2014). A next-generation smart contract and decentralized application platform. White Paper. https://doi.org/ 10.5663/aps.v1i1.10138.

56. Ethereum. (2018). Build unstoppable applications. Retrieved July 9, 2018, from https://ethereum.org/. Accessed 10 July 2018. 
57. Curran, B. (2018). Comparing Bitcoin \& Ethereum: UTXO vs account based transaction models. Retrieved December 26, 2018, from https://blockonomi.com/utxo-vs-account-based-transactionmodels/. Accessed 3 Jan 2018.

58. Mengelkamp, E., Gärttner, J., Rock, K., Kessler, S., Orsini, L., \& Weinhardt, C. (2018). Designing microgrid energy markets: A case study: The Brooklyn Microgrid. Applied Energy, 210, 870-880. https://doi.org/10.1016/j.apenergy.2017.06.054.

59. LO3 Energy. (2016). Brooklyn microgrid. Retrieved from http:// brooklynmicrogrid.com/. Accessed 3 May 2018.

60. Lapping, D. (2018). Top 10 smart energy startups to know in 2018. Retrieved December 26, 2018, from https://www.dis ruptordaily.com/top-10-smart-energy-startups/. Accessed 3 Jan 2018.

61. World Energy Council. (2017). The developing role of blockchain. https://doi.org/10.1017/s0020818300023973.

62. Green, J., \& Newman, P. (2017). Citizen utilities: The emerging power paradigm. Energy Policy, 105(February), 283-293. https:// doi.org/10.1016/j.enpol.2017.02.004.

63. Ioannis, K., Raimondo, G., Dimitrios, G., Gioia Rosanna, D., Georgios, K., Gary, S., et al. (2017). Blockchain in energy communities. Brussels. https://doi.org/10.2760/121912.

64. Lewin, K. (1946). Action research and minority problems. Journal of Social Issues, 2(4), 34-46. https://doi.org/10.1111/j. 1540-4560.1946.tb02295.x.

65. Dickens, L., \& Watkins, K. (1999). Action research: Rethinking Lewin. Management Learning, 30(2), 127-140. https://doi.org/ 10.1177/1350507699302002.

66. Sein, M. K., Henfridsson, O., Purao, S., Rossi, M., \& Lindgren, R. (2017). Action design research. MIS Quarterly, 35(1), 37. https://doi.org/10.2307/23043488.

67. Eden, C., \& Huxham, C. (2006). Researching organizations using action research. In S. R. Clegg, C. Hardy, T. B. Lawrence, \& W. R. Nord (Eds.), The SAGE handbook of organization studies (pp. 389-408). London: Sage Publications. https://doi.org/10.4135/ 9781848608030

68. Bahari, N., Maniak, R., \& Fernandez, V. (2015). Ecosystem business model design. In XXIVe Conférence Internationale de Management Stratégique (pp. 1-18). Paris: AIMS.

69. Walsham, G. (2006). Doing interpretive research. European Journal of Information Systems, 15(3), 320-330. https://doi.org/ 10.1057/palgrave.ejis.3000589.

70. Andrade, A. D. (2009). Interpretive research aiming at theory building: Adopting and adapting the case study design. The Qualitative Report, 14(1), 42-60.

71. Bhattacharya, H. (2012). Interpretive research. In L. M. Given (Ed.), The SAGE encyclopedia of qualitative research methods (pp. 465-467). Thousand Oaks: SAGE Publications. https://doi. org/10.4135/9781412963909.n130.

72. Koshy, E., Koshy, V., \& Waterman, H. (2011). Action research in healthcare. Thousand Oaks: Sage Publications.

73. Collier, D., \& Mahoney, J. (1996). Insights and pitfalls: Selection bias in qualitative research. World Politics, 49(01), 56-91. https:// doi.org/10.1353/wp.1996.0023.

74. Amit, R., \& Zott, C. (2015). Crafting business architecture: The antecedents of business model design. Strategic Entrepreneurship Journal, 9(4), 331-350. https://doi.org/10.1002/sej.

75. Weiller, C. M., \& Pollitt, M. G. (2013). Cambridge working platform markets and energy services (no. 1334), Cambridge.

76. van der Veen, R. A. C., \& Hakvoort, R. A. (2016). The electricity balancing market: Exploring the design challenge. Utilities Policy, 43, 186-194. https://doi.org/10.1016/j.jup.2016.10.008.

77. Cai, R. (2004). Trust and transaction costs in industrial districts. Virginia Polytechnic Institute and State University. Retrieved from http://scholar.lib.vt.edu/theses/available/etd-05222004232528/. Accessed 27 Nov 2017.
78. Zyskind, G., Nathan, O., \& Pentland, A. S. (2015). Decentralizing privacy: Using blockchain to protect personal data. In Proceedings-2015 IEEE security and privacy workshops, SPW 2015 (pp. 180-184). IEEE Computer Society. https://doi.org/10.1109/ spw.2015.27.

79. Chen, Z., Yu, Z., Duan, Z., \& Hu, K. (2017). Inter-blockchain communication. DEStech transactions on computer science and engineering. In 2nd International conference on computer science and technology (CST 2017) (pp. 448-454).

80. Raval, S. (2016). Decentralized applications (Vol. 53). Sebastopol: O'Reilly. https://doi.org/10.1017/cbo9781107415324.004.

81. Herweijer, C., Waughray, D., \& Warren, S. (2018). Building block(chain)s for a better planet. World Economic Forum. http:// www3.weforum.org/docs/WEF_Building-Blockchains.pdf.

82. Diestelmeier, L. (2017). Regulating for blockchain technology in the electricity sector: Sharing electricity-And opening Pandora's Box? In Proceedings of the 16th annual IAS-STS conference on critical issues in science and technology studies, Graz.

83. Lauslahti, K., Mattila, J., \& Seppala, T. (2018). Smart contractsHow will blockchain technology affect contractual practices? Ssrn. https://doi.org/10.2139/ssrn.3154043.

84. Smart Grid Working Group. (2018). Smart grid working group final report, Helsinki.

85. DIAS Oy. (2018). A globally unique digital system for housing trade is being created in cooperation between banks, the estate agency sector, a technology company and state officials. Retrieved May 4, 2019, from https://www.sttinfo.fi/tiedote/aglobally-unique-digital-system-for-housing-trade-is-being-cre ated-in-cooperation-between-banks-the-estate-agency-sector-atechnology-company-and-state-officials?publisherId= 69817177\&releaseId=69847522. Accessed 10 Apr 2018.

86. Wang, H., Chen, K., \& Xu, D. (2016). A maturity model for blockchain adoption. Financial Innovation, 2(1), 12. https://doi. org/10.1186/s40854-016-0031-z.

87. Hitt, M. A., Ireland, R. D., Sirmon, D. G., \& Trahms, C. A. (2008). Strategic entrepreneurship: Creating value for individuals, organizations, and society. Strategic Entrepreneurship Journal, 2(3), 175-190. https://doi.org/10.4135/9781452229805. n587.

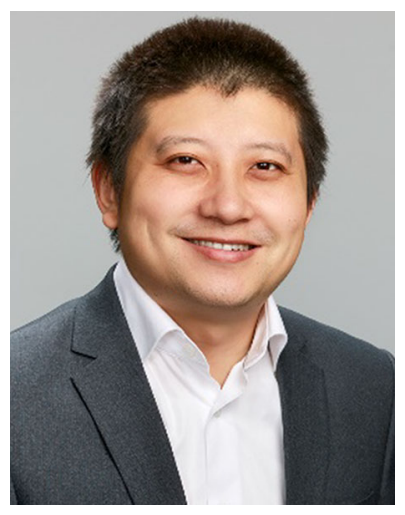

Yueqiang $\mathrm{Xu}$ is a project researcher and $\mathrm{Ph} . \mathrm{D}$. candidate at Martti Ahtisaari Institute, the University of Oulu, Finland. His research areas include smart grid, digitalization of energy and ICT related domains. His professional experience in the energy industry includes conducting research and consulting projects for energy utilities, ICT and smart grid solution providers and regulatory organizations, for example, World Energy Council, Microsoft, EDF (France), ABB (Global), ADEME (France), Australian Renewable Energy Agency (Australia), BEAMA (UK), Dong Energy (Denmark), Opower (USA) and the European Union. 


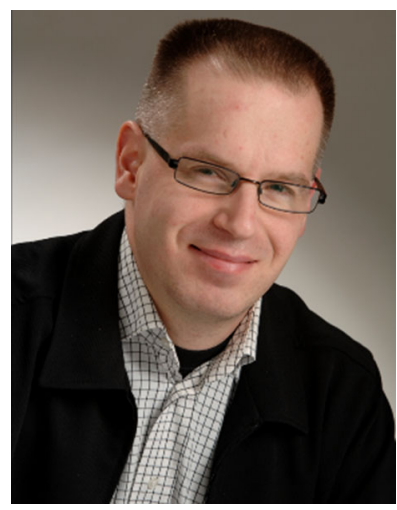

Dr. Petri Ahokangas is a senior research fellow and the leader of FUTURALIS research group at Martti Ahtisaari Institute in the University of Oulu, Finland. FUTURALIS focuses on future digital businesses models and ecosystems. He is also an adjunct professor of international software entrepreneurship at the University of Oulu. His research interests are in how innovation and technological change affect the international business creation, transformation, and strategies in highly technology-intensive or software-intensive business domains. He is co-editor-in-chief of Journal or Business Models, and he has over 140 publications in scientific journals, books, conference proceedings, and other reports. He is actively working in several ICT-focused research consortia leading the business research activities. Prior to his academic career, he worked in the telecommunications software industry. He is also a serial entrepreneur and active consultant in the field on digitalization, strategy and internationalization.

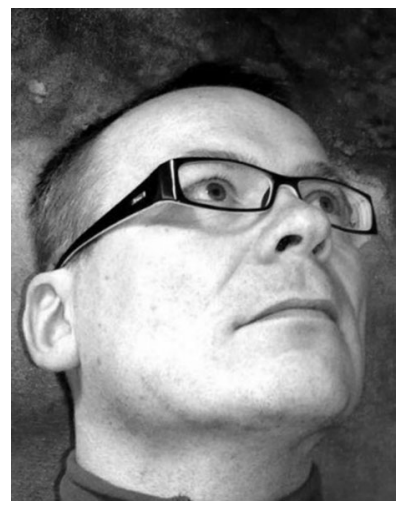

Dr. Seppo Yrjölä is a Senior Principal Innovator at Nokia Corporate Strategy and Development, in Finland. He holds a M.Sc. degree in Electrical Engineering and a Dr. Sc. degree in Telecommunications Engineering from the University of Oulu. He conducts multidisciplinary research combining technology, business and regulatory aspects for the development of future mobile communication systems.

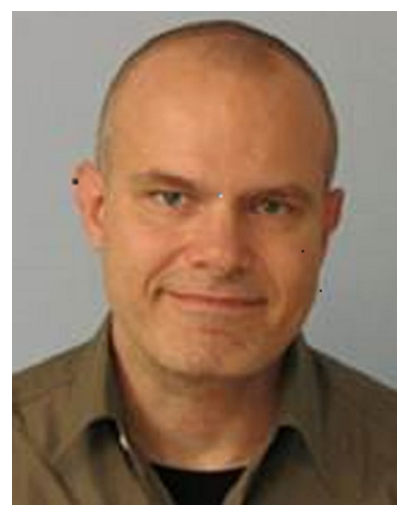

Dr. Timo Koivumäki is a professor of digital service business at Martti Ahtisaari Institute, University of Oulu. Previously he has worked as a research professor of mobile business applications at VTT and at the University of Oulu, as a professor of information and communication business and as a research professor of electronic commerce at the University of Oulu. All in all, Koivumäki has over 20 years of experience in the field of digital business. His research interests include consumer behavior in digital environments, user-driven innovation, digital service business, digital marketing and strategic networking. Koivumäki has been active in various duties (e.g. planning, managing and conducting research) in many national and international research and development projects. Koivumäki has also published in numerous top-level academic journals.

Publisher's Note Springer Nature remains neutral with regard to jurisdictional claims in published maps and institutional affiliations. 